\title{
Performance of Participants on Multiple Answers Type Item in Research Methodology as a Function of Discipline, Gender and their Interaction
}

\author{
DN Sansanwal \\ Department of Education, Devi Ahilya University, Indore, Madhya Pradesh-452001, India
}

dnsansanwal@email.com

ARTICLE INFORMATION

Received: August 08, 2020

Revised: August 27, 2020

Accepted: September 04, 2020

Published Online: October 21, 2020

Keywords:

Types of Items, Multiple Answers Type Items

\begin{abstract}
Examination is a part and parcel of Teaching-Learning Process. In examination or tests different types of question are asked by teachers. These are Essay, Short Answer, Multiple Choice, Fill-in the Blanks, and Matching Types. These are not very suitable for Open Book Examination. Multiple Answers Type Items in Research Methodology were developed for the research. It is a new type of question which can be used by school, College and University teachers irrespective of the subject taught by them. The objective of this research was to study the influence of Discipline, Gender and their interaction on Performance of participants on Multiple Answers Type Items in Research Methodology. The Hypothesis formulated in null form was there is no significant influence of Discipline, Gender and their interaction on Performance of participants on Multiple Answers Type Items in Research Methodology. This study was conducted on Sample of 423 Deans, Professors, Associate Professors, Assistant Professors, Research Fellows and Postgraduate students from 26 states and six countries. Data were collected online using WhatsApp and emails during Covid-19 period. The findings were: (1) Social Science participants were found to have better understanding of Research Methodology than Science as well as Humanities participants. Further Science as well as Humanities participants were found to similar understanding of Research Methodology. (2) Male and Female Participants were found to perform equally well on Multiple Answers Type Items in Research Methodology. (3) Performance on Multiple Answers Type Items in Research Methodology was found to be independent of interaction between Discipline and Gender of Participants.
\end{abstract}

\section{Introduction}

Destiny of India is being shaped in her classrooms was scripted by Kothari (1966). In classrooms, examination is part and parcel of Teaching - Learning Process. People have been criticizing examination system. All types of allegations are made but still it is continuing and people use examination results for admission into higher classes and employment. But some agencies have started conducting their own examination for selection purpose. The agencies are UPSC, IIT, IIM, NCERT, UGC, etc. Also many schools and Universities have also started conducting entrance test for admitting students in different courses. At present annual / semester examinations are of three hours. Question papers normally contain long answer type questions. Some Universities have a provision of giving Objective type questions also. The different types of Objective type questions are Multiple Choice, Fill-in-Blanks, Matching, short answer type, etc. Questions asked in different examinations are not to be answered using books. That is, Open Book Examination is hardly conducted by majority of Universities and Colleges in India except in IITs, IISc., IIMs, etc. Teachers of Department of Education, Devi Ahilya University, Indore were giving Open Book Examination. Students used to fail but still they liked it. Multiple Discriminate Type Item was developed by Sansanwal and Tyagi (2011) where the guessing reduced substantially. To answer this type of question, learner must have understanding of the content without which one cannot answer the question correctly. This type of question was very appropriate for Open Book Examination.

Normally there is only one correct answer in Multiple Choice Item. Why cannot there be more than one correct answer in one question? Researcher started 
thinking and has developed large number of Multiple Answers Type Item with more than one correct answer. Such items are good for testing higher mental ability. Students may be given freedom to use books or any other source which they want. So Multiple Answers Type items are appropriate for Open Book examination which can assess understanding and application ability of learners. During lockdown period such items may be used for examination purpose. Items with more than one correct answer can be used in all subjects including Music, Dance, Panting, Languages, Engineering, Medical, Mathematics, Physics, Chemistry, Botany, Zoology, History, Economics, Political Science, Statistics, etc.

\section{Objective}

The objective of this study was:

- To study the influence of Discipline, Gender and their interaction on Performance of participants on Multiple Answers Type Items in Research Methodology.

\section{Hypothesis}

The following was the Hypothesis of this study:

- There is no significant influence of Discipline, Gender and their interaction on Performance of participants on Multiple Answers Type Items in Research Methodology.

\section{Sample}

Sample comprised of 423 Deans, Professors, Associate Professors, Assistant Professors, Research Fellows and Postgraduate students from 26 states and six countries. The states were Assam, Ander Pradesh, Arunachal Pradesh, Bihar, Chandigarh, Chhatisgarh, Delhi, Gujarat, Haryana, Jammu and Kashmir, Jharkhand, Karnataka, Kigali, Kerala, Meghalaya, Maharashtra, Madhya Pradesh, Nagaland, Odisha, Punjab, Sikkim, Telangana, Tejpur, Tamil Nadu, Uttar Pradesh, Uttarkhand, and West Bengal. Also participants were from Australia, Bhutan, Figgi, Nepal, Nigeria, and USA. Different subjects to which participants belonged were Anthropology, Bio-Chemistry, Biotechnology, Biology, Botany, Chemistry, Commerce, Computer Science, Education, Economics, Electronics, English, Geography, Hindi, History, Home Science, Law, Library Science, Mathematics, Management, Mass communication, Mental Health, Microbiology, Nursing, Physics, Political Science, Psychology, Physical Education, Public Health, Sports Science, Special Education, Sociology, Statistics, Travel \& Tourism Management, Zoology. Overall participants were from 35 subjects. There were 202 Male participants and 221 Female participants. So sample was representative of Gender. Out of 423 participants, 324 were Dean, Professors, Associate Professors, and Assistant Professors while 99 were Research Fellows and Postgraduate students. Participants belonged to Central, State, Deem-to-be Universities and Private Universities and Colleges affiliated to these Universities.

\section{Tool}

The test was developed by the researcher. It consisted of two questions from Research Methodology. Research Methodology is taught to students as it is part and parcel of Pre-Ph.D. Course in all Universities of India. Irrespective of subject, each student tend to enroll for Ph.D. in any subjects has to undergo PrePh.D. Course in that subject. The questions given to participants were as follows:

\section{Which of the Following Statement(s) is/are Correct?}

A. The degree of freedom can be in fraction mathematically.

B. The degree of freedom is always in whole number.

C. Conceptually degree of freedom is in whole number.

D. Degree of freedom is always less than the total size of sample.

E. The degree of freedom is sometime less than the total sample.

F. There is no concept of degree of freedom in Historical Researches.

\section{Basis(es) of Formulation of Hypothesis is/are}

A. Textbook read by the researcher.

B. Papers related to the area of research published in e-journals.

C. Papers read by the researcher from the journals.

D. Online researches available.

E. Related researches available on Shodhganga.

F. Analysis of collected Data.

G. Theory underlying the problem of research.

In both the questions, correct answers were more than one. In case of question 1 , the correct answers were A, $\mathrm{C}, \mathrm{D}$, and $\mathrm{F}$ but for question 2, it was B, E and G. For 
each correct answer, one mark was given and for each wrong answer 0.25 marks were deducted. This test was not standardized.

\section{Procedure of Data Collection}

Data were collected online by sending questions to people through WhatsApp as well as email. The researcher thought that during lockdown it is not possible to visit institutes of higher education for collecting data. After sending questions to Dean, Professors, Associate Professors, Assistant Professors, Research Scholars and Postgraduate students belonging to different Universities, Colleges and Deem-to-be Universities, respondents were requested many a time to answer the questions. Some respondents refused to answer and stated that they did not study Research Methodology as part of their course. There was no time limit for answering the questions. Also there was no restrictions as to whether they refer to books, websites, discuss with their friends or teachers, etc. It means that there was $100 \%$ freedom for the respondents.

\section{Results and Interpretation}

\section{Influemce of Discipline, Gender \& Their Interaction on Performance on Multiple Answers Type Items in Research Methodology of Participants}

The objective was to study the influence of Discipline, Gender and their interaction on Performance of participantson Multiple Answers Type Items in Research Methodology. Social Science, Science and Humanities are three levels of Discipline while Male and Female were the two levels of Gender. Thus the data were analysed with the help of 3X2 Factorial Design ANOVA and the results are given in Table 1.

Table 1: Summary of 3X2 Factorial Design ANOVA of Performance on Multiple Answers Type Items in Research Methodology of participants

\begin{tabular}{|l|l|l|l|l|l|}
\hline $\begin{array}{l}\text { Source of } \\
\text { Variance }\end{array}$ & df & SS & MSS & F-Value & Remark \\
\hline Discipline (A) & 2 & 35.18 & 17.59 & 3.88 & $\mathrm{p}<0.05$ \\
Gender (B) & 1 & 0.01 & 0.01 & 0.002 & $\mathrm{~ns}$ \\
AXB & 2 & 1.55 & 0.78 & 0.17 & $\mathrm{~ns}$ \\
Error & 417 & 1892.18 & 4.54 & & \\
Total & 422 & & & & \\
\hline
\end{tabular}

\section{Influence of Discipline on Performance of Participants on Multiple Answers Type Items in Research Methodology}

From Table 1, it can be seen that the F-value for Discipline is 3.88 which is significant at 0.05 level with $\mathrm{df}=2 / 417$. It reflects that the mean scores of Performance on Multiple Answers Type Items in Research Methodology of participants belonging to Social Science, Science and Humanities differ significantly. So there was a significant influence of Discipline on Performance of participants on Multiple Answers Type Items in Research Methodology. Thus the null hypothesis that there is no significant influence of Discipline on Performance of participants on Multiple Answers Type Items in Research Methodology is rejected. In order to know participants of which Discipline were found to have significantly higher Performance on Multiple Answers Type Items in Research Methodology, the data were further analysed with the help of t-test and the results are given in Table 2.

Table 2: Discipline-wise M, SD, N and t-values of Performance on Multiple Answers Type Items in Research Methodology of participants

\begin{tabular}{|l|l|l|l|l|l|}
\hline Discipline & $\mathbf{M}$ & SD & $\mathbf{N}$ & Science & Humanities \\
\hline Social Science & 3.55 & 2.15 & 324 & $2.03^{* *}$ & $2.21^{* *}$ \\
\hline Science & 2.92 & 1.75 & 53 & & 0.31 \\
\hline Humanities & 2.80 & 2.31 & 46 & & \\
\hline
\end{tabular}

${ }^{* *}$ Significant at 0.05 level

From Table 2, it can be seen that the t-value for Social Science and Science Groups is 2.03 which is significant at 0.05 level with $\mathrm{df}=375$. It indicates that the mean scores of Performance on Multiple Answers Type Items in Research Methodology of participants from Social Science and Science Groups differ significantly. Further the mean score of Performance on Multiple Answers Type Items in Research Methodology of Social Science participants is 3.55 which is significantly higher than those of Science participants whose mean score of Performance on Multiple Answers Type Items in Research Methodology is 2.92. It may, therefore, be said that Social Science participants were found to have better understanding of Research Methodology than their counter parts of Science participants.

The t-value for Social Science and Humanities Groups is 2.21 which is significant at 0.05 level with 
$\mathrm{df}=368$ (Vide Table 2). It indicates that the mean scores of Performance on Multiple Answers Type Items in Research Methodology of participants from Social Science and Humanities Groups differ significantly. Further the mean score of Performance on Multiple Answers Type Items in Research Methodology of Social Science participants is 3.55 which is significantly higher than those of Humanities participants whose mean score of Performance on Multiple Answers Type Items in Research Methodology is 2.80. It may, therefore, be said that Social Science participants were found to have better understanding of Research Methodology than their counter parts of Humanities participants.

The $\mathrm{t}$-value for Science and Humanities Groups is 0.31 which is not significant (Vide Table 2). It indicates that the mean scores of Performance on Multiple Answers Type Items in Research Methodology of participants from Science and Humanities Groups did not differ significantly. It may, therefore, be said that Science as well as Humanities participants were found to similar understanding of Research Methodology.

\section{Influence of Gender on Performance of participants on}

\section{Multiple Answers Type Items in Research Methodology}

From Table 1, it can be seen that the F-value for Gender is 0.002 which is not significant. It indicates that the mean scores of Performance on Multiple Answers Type Items in Research Methodology of Male and Female participants did not differ significantly. So there was no significant influence of Gender on Performance of participants on Multiple Answers Type Items in Research Methodology. Thus the null hypothesis that there is no significant influence of Gender on Performance of participants on Multiple Answers Type Items in Research Methodology is not rejected. It may, therefore, be said that both Male and Female Participants were found to perform equally well on Multiple Answers Type Items in Research Methodology.

\section{Influence of interaction between Discipline and Gender on Performance on}

\section{Multiple Answers Type Items in Research Methodology of participants}

F-value for interaction between Discipline and Gender is 0.17 which is not significant (Vide Table 1). It indicates that the mean scores of Performance on Multiple Answers Type Items in Research Methodology of Male and Female participants belonging to Social Science, Science and Humanities did not differ significantly. So there was no significant influence of interaction between Discipline and Gender on Performance of participants on Multiple Answers Type Items in Research Methodology. Thus the null hypothesis that there is no significant influence of interaction between Discipline and Gender on Performance of participants on Multiple Answers Type Items in Research Methodology is not rejected. It may, therefore, be said that performance on Multiple Answers Type Items in Research Methodology was found to be independent of interaction between Discipline and Gender of participants.

\section{Discussion}

Social Science participants were found to have better understanding of Research Methodology than their counter parts of Science as well as Humanities participants. On the other hand Science and Humanities participants were found to have same degree of understanding of Research Methodology. Social Science consists of Psychology, Geography, Economics, Criminology, Education, Management, Linguistic, etc. Participants of Social Science have studied Research Methodology because it was a part of their course. Not only this, but they had also studied Research Methodology during their Pre-Ph.D. course. On the other hand, Science and Humanities participants did not study Research Methodology in the same way as done by participants of Social Science. The content of Pre-Ph.D. course work of Science and Humanities participants is quite different. The orientation of Science and Humanities participants of Research Methodology is quite different than those of Social Science participants. Because of above stated reason Social Science participants were found to have better understanding of Research Methodology than their counter parts of Science as well as Humanities participants, and Science and Humanities participants were found to have same degree of understanding of Research Methodology.

Both Male and Female Participants were found to perform equally well on Multiple Answers Type Items in Research Methodology. It indicates that this 
type of item is Gender free and suits to both Males as well as Females. Research Methodology is common to both Males and Females. The same content is taught to both Males as well as Females. During teaching, teachers do not differentiate between Male and Female participants. In examination, the same question paper is given to them. The books are not written separately for Males and Females. Due to similarities, both Male and Female might have performed equally well on the Multiple Answers Type Items in Research Methodology. Multiple Answers Type Items can be used for assessing understanding of Research Methodology of both Male and Female Participants.

Performance on Multiple Answers Type Items in Research Methodology was found to be independent of interaction between Discipline and Gender of Participants. It further indicates that Male and Female Participants belonging to Social Science, Science and Humanities were found to understand Research Methodology to the same extent. This might be because Research Methodology, if part of the course, is taught with the help of same method to Male and Female Participants. Teachers do not teach Research Methodology differently to Male and Female Participants. The content taught is also the same for Male and Female Participants. Even the examination pattern is not different for Male and Female Participants. Both Male and Female Participants refer to the same books and website material. Even the syllabus also remains same for Male and Female Participants. On the other hand, the Study Habits of Male and Female Participants differ. Their thinking ability, expression power, reading comprehension, etc. also differ. These factors did not seem to affect the understanding of Research Methodology of Male and Female Participants. Therefore, Male and Female Participants belonging to Social Science, Science and Humanities were found to perform to the same extent on Multiple Answers Type Items in Research Methodology. It may, therefore, be said that Multiple Answers Type Items in Research Methodology can be used for Male as well as female Participants belonging to Social Science, Science and Humanities Disciplines.

\section{Conflict of Interest}

There is no conflict of interest.

\section{References}

Kothari, D.S. (1966). National Education Commission, MHRD, New Delhi.

Sansanwal, D.N. \& Tyagi, S.K. (2011). Multiple Discriminent Type Item - A New Weapon in Testing Arsenal. GCTE Journal Of Research And Extension In Education, 6(1), 48-57.

\section{司 \\ CHITKARA}

\section{Issues and Ideas in Education}

Chitkara University, Saraswati Kendra, SCO 160-161, Sector 9-C, Chandigarh, 160009, India

\section{Volume 8, Issue 2}

September 2020

ISSN 2320-7655

Copyright: [C 2020 DN Sansanwal] This is an Open Access article published in Issues and Ideas in Education (Issues Ideas Educ.) by Chitkara University Publications. It is published with a Creative Commons AttributionCC-BY 4.0 International License. This license permits unrestricted use, distribution, and reproduction in any medium, provided the original author and source are credited. 